\title{
Enzyme Engineering in Biomimetic Compartments
}

Pierre-Yves Colin, Anastasia Zinchenko and Florian Hollfelder*

${ }^{1}$ Department of Biochemistry, University of Cambridge, Cambridge CB2 1GA, UK

${ }^{*}$ Correspondence to fh111@cam.ac.uk, (+44) 1223766048 


\section{Highlights}

- successful experiments demonstrate ultrahigh throughput enzyme evolution in microdroplets

- water-in-oil emulsion droplets compartmentalize genotype and phenotype

- microfluidic devices produce monodisperse droplets at rates $>1 \mathrm{kHz}$ for quantitative assays

- droplets are sorted on-chip and double emulsions and gel-shell beads by flow cytometry 


\section{Abstract}

The success of a directed evolution approach to creating custom-made enzymes relies in no small part on screening as many clones as possible. The miniaturisation of assays into pico- to femtoliter compartments (emulsion droplets, vesicles or gel-shell beads) makes directed evolution campaigns practically more straightforward than current large scale industrial screening that requires liquid handling equipment and much manpower. Several recent experimental formats have established protocols to screen more than 10 million compartments per day, representing unprecedented throughput at low cost. This review introduces the emerging approaches towards making biomimetic man-made compartments that are poised to be adapted by a wider circle of researchers. In addition to cost and time saving, control of selection pressures and conditions, the quantitative readout that reports on every library members and the ability to develop strategies based on these data will increase the degrees of freedom in designing and testing strategies for directed evolution experiments. 


\section{Introduction}

The cellular compartment plays a crucial role in evolution, by demarcating the boundary of one individual 'evolutionary unit' and distinguishing it from many other cells that are in competition during Darwinian evolution. Directed enzyme evolution [1, 2] tries to adapt Darwinian principles, to complement or go beyond rational design of catalysts. Instead of general cell survival in natural evolution, artificial evolution is directed towards improvement of a specific function (e.g. thermostability or catalytic efficiency) under non-natural conditions. Avoidance of in vivo survival selections with cells widens the scope of reactions that can be evolved beyond metabolically relevant processes and bypasses complications that arise when cells evade selection pressure in unexpected ways. Biomimetic compartments maintain the key feature of cells, the linkage of genotype and phenotype [3], and thereby allow relating the functional trait of a protein (such as catalytic activity) to the nucleic acid sequence encoding it (thus providing access to the identity of a library member after selection).

Figure 1 shows the archetype of one such reductionist compartment that contains the DNA and the catalytic protein expressed from it: a substrate is co-compartmentalised with the protein catalyst, multiple turnovers occur and selections can be based on product detection. When selected for a phenotype, the DNA coming with it reveals the identity of the catalyst. After the compartment is broken up, the DNA of the selected clones is recovered and analyzed - or fed into further rounds of randomization and selection. Just as cells survive environmental changes or competition in evolution, compartments that contain more reaction product will be selected and 'survive'. However, the survival criterion is molecularly defined (e.g. by product concentration - allowing direct selections for catalytic turnover), only one chosen protein (as opposed to a whole organism) is stringently put under selection pressure and the selection threshold is deliberately adjusted by the experimenter.

Such in vitro compartments are easily made by dispersing an aqueous solution in an oil phase and can be stabilised by surfactant molecules. Large numbers of such droplets $\left(\sim 10^{7}-10^{9}\right.$ in one experiment) can now be produced in a variety of formats (Table 1 ). Not only do larger numbers of experiments 
become possible in highly parallelised fashion, but the cost per assay is also dramatically reduced by $\sim 10^{6}$-fold [4], as they are carried out on the femto- to picoliter scale in droplets. Directed evolution campaigns carried out at higher throughput are more likely to be successful, making droplet technologies a promising tool for accelerated library selections. After more than a decade devoted to establishing protocols to generate a variety of compartments, this approach is now poised to become more widely used.

\section{Polydisperse Emulsion Compartments}

(i) Water-in-oil emulsions. The potential of emulsion compartments for molecular evolution was first explored by Tawfik and Griffiths [5]. Simple emulsion droplets can be prepared from an oil/water mixture using a stirring bar [5], an emulsifier [6] or simply by using custom-made tips with filters ( 10 $\mu \mathrm{m})$ and straightforward up-and-down pipetting [7] (Table 1). Such polydisperse compartments (i.e. with wide variety of sizes) are suitable for engineering DNA polymerases or DNA-modifying enzymes, as the "readout" is obtained from amplified DNA coding for improved variants (that are then gradually enriched over iterative selection rounds). For example, polymerases expressed in E. coli were evolved for higher thermostability or enhanced resistance to inhibitors [8], or to synthetize polymers containing unnatural nucleotides [9]. The development of compartmentalised partnered replication (CPR) broadened the target activities to tRNA synthetases (e.g. to genetically incorporate non-natural amino-acids) and may be used in the future for selecting other traits that can be linked to DNA polymerase expression [10].

(ii) Double emulsions. For enzymes that do not modify DNA, but process small molecules, other assays have to be implemented, e.g. based on an optical readout. Enzymes that turn over substrates generating a fluorescent product trapped inside the compartment can be analyzed by flow cytometry [11]. However, a second emulsification has to be brought about to generate water-in-oil-in-water double emulsions with overall aqueous character, so that they can be sorted by fluorescence-activated cell sorter (FACS) [11]. This setup has been used to increase catalytic efficiencies of $\beta$-galactosidase [12], thiolactonases [13] or to improve catalytic detoxification of nerve agents by a phosphotriesterase [14]. However, as a result of two subsequent 
emulsification steps these compartments are highly polydisperse in size. Since the droplet volume has a cubic dependence on its radius, already small variations in droplet size can result in large concentration differences between compartments, even though the same amount of product is produced by a compartmentalised catalyst. Under these circumstances it will be difficult to carry out quantitative assays (even when normalization is attempted by coexpression of a fluorescent protein [13]), especially when only incrementally improved mutants are contained in the library under selection, requiring precise distinction as the basis for the selection decision.

\section{Monodisperse Emulsion Compartments}

To enable quantitative measurements control over concentration measurements is essential. To this end microfluidic techniques were explored to generate compartments with precisely defined, uniform size. The notion of combining unit operations (e.g. mixing, diluting, adding, sorting) provided a framework for implementing classical laboratory sample handling steps en miniature and at ultrahigh throughput, and forms the basis for the design of complex workflows on-chip [15].

(i) Water-in-oil emulsions. Water-in-oil emulsion droplets (Table 1) are generated in poly(dimethylsiloxane) (PDMS) microfluidic chips [16, 17], in which an oil flow emulsifies an aqueous stream (Figure 2). Several chip designs (e.g. T-junction or flow focusing, reviewed in [18, 19]) have been described to generate compartments with minimised variations in size distribution. Microdroplets are generally produced at $\mathrm{kHz}$ frequencies but generation of femtolitre drops by jetting was demonstrated in the $\mathrm{MHz}$ range [20]. Emulsions are usually generated in oil but are incompatible with FACS instruments that employ aqueous sheath fluids. Therefore, to separate droplet populations according to product fluorescence on-chip devices for fluorescence-activated droplet sorting have been developed (Figure 2). Microdroplets are deflected by dielectrophoresis [21] or acoustic waves [22] and are generally operated at frequencies around $\sim 2 \mathrm{kHz}$ (even though accurate sorting has also been demonstrated at $40 \mathrm{kHz}$ [23]).

(ii) Double emulsions. To limit drop-to-drop volume differences, monodisperse water-in-oil-in-water double emulsions can be produced in capillary devices 
[24] or PDMS chips [25] (Table 1). As above, such double emulsions are first produced as water-in-oil emulsion in hydrophobically modified channels, followed up by a second emulsification step in channels with hydrophilic surfaces. Hydrophobic or hydrophilic device coating promotes wetting with the carrier fluid and prevents droplets adherence to the channel walls. Two different channel coatings can be difficult to implement when double emulsions are produced in a single PDMS chip [25]. Using two separate chips (one hydrophobic-modified and a second hydrophilic-modified) instead facilitates the workflow and allows integration of additional operations (e.g. stopping enzymatic reactions by an off-chip heating step) [26].

(iii) Gel-Shell Beads (GSBs). Agarose microspheres were recently adapted to selections for catalysis: single bacteria were encapsulated with substrate in microdroplets and lysed to liberate the protein of interest. Upon lowering the temperature, additional droplet components, agarose and alginate, solidify creating agarose microspheres $(\varnothing \sim 25 \mu \mathrm{m})$ in droplets and 'immortalising' the monoclonal nature of the original droplet. The deposition of layers of polyelectrolytes on the surface of these microspheres creates a size-selective shell (with permeability only for molecules <2 kDa [27]), so that reaction product can be captured together with enzyme and its encoding plasmid DNA, when GSBs are selected by flow cytometry. The semi-permeable boundary of GSBs presents advantages over emulsions: (I) it allows buffer exchange (e.g. for successive incompatible reactions) or addition of small molecules (e.g. triggering subsequent reactions), facilitating multistep systems such as cascade reactions; (ii) substrates and products can diffuse in and out, while enzymes are retained within the compartments making GSBs an alternative for enzyme immobilization that may replace covalent surface attachment of the catalyst by 'caging'.

\section{Options for expression of the protein of interest}

Directed-evolution relies on iterative cycles of gene diversification, selection and gene recovery (Figure 2). In contrast to FACS analysis where only intact natural cells can be used for enzymatic reaction detections, protocols for man- 
made droplets can be integrated with different protein expression systems (Figure 2).

Display of the protein of interest on yeast or bacteria provides a robust solution for delivery of protein and coding gene into droplets. Each cell expresses a different enzyme variant on their surface and single species are compartmentalised. Here the droplet boundary retains reaction product resulting from turnover by the displayed protein (Figure 2) and marks clones encoding successful catalysts, which would be impossible in bulk. Successful directed-evolution in microfluidic droplets containing a yeast-displayed enzyme was used to increase the activity of horseradish peroxidase (HRP) towards Amplex UltraRed by 10-fold [4]. Microfluidic droplets were also shown to be suitable for monitoring the activity of secreted enzymes (Figure 2), e.g. for metabolite consumption (xylose) or production (L-lactate) by yeasts [28] or the screening of microorganisms secreting a-amylase [29].

As the majority of proteins cannot be displayed on cells or secreted efficiently, screening of cytoplasmically expressed proteins as cell lysates is a widely used alternative. Lysis ensures that the enzyme encounters its substrate, even if it cannot cross the cell membranes. A workflow to miniaturise this process in a single-cell lysate protocol was implemented [30]. Single cells (each cell representing one library member) were compartmentalised with lysis reagents and substrate, so that after cell disintegration (that occurs within minutes after droplet formation) compartmentalised enzymatic reactions catalyzed by the protein produced by a single cell can be monitored and subsequently sorted. Catalysts can be incubated in a delay line (with several point measurements) [30] or - for slow reactions - after offline storage for several days [31]. This procedure was exemplified by the successful evolution of a promiscuous hydrolase [30] in two rounds of genetic diversification and selection which led to improve expression and activity by an order of magnitude each. The genotype-phenotype linkage provided by the droplet boundary was maintained until de-emulsification after selection. The use of a high copy plasmid enabled efficient "storage" genes coding for improved variants by directly transforming plasmids into highly competent E.coli (avoiding PCR amplification). If microcolonies are grown in droplets prior substrate addition (e.g. by picoinjection [32]) bacteria can be directly 
recovered after de-emulsification [33]. However this protocol requires either substrates able to cross the cell membrane or that at least a fraction of the in the microcolony lyse within the droplet. In both cases the lack of control over concentration of catalysts encountering substrate may bias selections in directed-evolution experiments.

In vitro transcription/translation (Figure $2 \mathrm{c}$ ) is particularly attractive when overexpression in cellular hosts is toxic, for incorporation of non-natural amino acids/cofactors or to avoid biological background [34]. Expression can be performed from single genes in droplets $[5,6,35]$, typically yielding $>10^{4}-10^{5}$ molecules [6, 36]. In vitro expression can be boosted by generating multiple copies of the DNA template ( 30,000 after emulsion PCR [37]), which also avoids large variations in expression efficiency from a unique DNA molecule [37]. Such complete in vitro systems require assemblies of multiple microfluidic operations, i.e. amplification, expression and sorting [37, 38].

\section{What can go wrong? - and ways to fix it}

(i) Leakage. The boundary of the droplet compartment is never ideally impermeable: hydrophobic molecules eventually leave the aqueous environment and partition into the surrounding oil phase. Even when mineral oils are replaced by fluorous oils - designed to act as a 'third phase' [39] with hydrophobic and lipophobic properties to prevent leaking of assay reagents [40, 41]) - small molecules escape [19, 42, 43]. Leakage of e.g. product molecules compromises faithful measurement of turnover and makes hits harder or impossible to detect and separate from undesired clones. Chemical modification of fluorescent leaving groups without affecting their fluorescence properties can improve their retention, e.g. adding a charged sulfate group to a coumarin leaving group [44, 45]. Addition of BSA [43] or small molecules (e.g. $\beta$-cyclodextrin) to the aqueous phase, adjustment of $\mathrm{pH}$, variation of the surfactant concentrations and choice of the fluorous carrier oil are parameters that can improve the retention of fluorophores by several orders of magnitude [46].

(ii) Compatibility between the droplet formation protocol and the in vitro expression system. Compatibility of fluorescent molecules or enzymatic reactions with various oil/surfactant conditions can rapidly be tested by image 
analysis of polydisperse droplets produced in bulk. Better oil/surfactant compatibilities with fluorescent molecules show stronger size/fluorescence dependences [47].

\section{Towards synthetic cells}

Droplet compartments can be seen as minimalist versions of a natural cell, maintaining the elements necessary for the directed evolution of an encapsulated protein [48]. This analogy can be extended, when compartments can be made even more cell-like by replacing the emulsion interface with a lamellar phase lipid bilayer in liposomes. To make liposomes, water is first emulsified in oil (containing lipids as surfactants), resulting in inverted micelles. The micelles are added to a lipid-saturated oil phase, poured on top of an aqueous solution, forming a lipid monolayer at the interface. Liposomes are simply formed when inverted micelles pass through the interface by sedimentation [49]. Now proteins that require embedding in hydrophobic environment of cell membranes to be functional become amenable to engineering (receptors, membrane transporters, pore-forming proteins) $[50,51]$.

Beyond the representation of a genotype-phenotype linkage droplets would become fully 'alive', if the ability to self-replicate can be passed on to daughter droplets. A step towards such a system has been taken using $Q \beta$ replicase that can reproduce its own coding single-stranded RNA in compartments [52]. Fusion of droplets containing monoclonal replicated RNA with in vitro translation mixture droplets enabled translation before "droplet division" by filtering and transmission of genetic information. An increase of fitness (defined as replication ability) and the successive fixation of mutations along the evolutionary trajectory demonstrates that Darwinian features emerge spontaneously in synthetic compartments that mimic cell division [52].

\section{Future directions}

(i) Smaller is better. Microdroplet volumes are in the range of $10^{-12}-10^{-15} \mathrm{~L}$, so incredibly small amounts or reagents are needed. Micro- to millimolar concentrations of product are reached with few hundred thousands of 
turnovers of enzyme, making this platform also extraordinarily sensitive, so that even weak activities can be detected. Miniaturisation to the pico- or femtoliter level in droplet compartments provides access to much larger numbers of experiments, with relatively simple means: up to $\sim 10^{9}$ when droplets are produced in bulk or $\sim 10^{7}$, when microfluidics are used to improve the precision for more quantitative studies. Even at the lower end, $>10^{3}$-fold more single reactions can be carried out than by colony screening or robotic liquid handling technologies.

In the future this highly economical approach will become especially powerful, when connected to high-throughput sequencing to draw up sequence-function relationships on the basis of deep mutational scanning [53]. Classical mutational studies are usually limited to few residues around the active site, deep mutational scanning will enable a more complete survey, by identifying distant mutations that have dramatic effect on protein fitness (e.g. by stabilization [54]) and by characterizing 'fitness landscapes' [55]. Protocols are so far limited to display methods or assays based on survival $[56,57]$ but the types of target proteins could be expanded (i.e. to biocatalysts) by using compartmentalization formats. Finally droplet-on-demand formats in which enzymatic reactions are monitored as a function of substrate concentration or other parameters can be used to determine biophysical or steady-state kinetic parameters fully unsupervised much give much more rapid access to data that is cumbersomely obtained in current formats [69, 70].

(ii) Entertaining parallel trajectories for evolution in high throughput systems. Directed-evolution in the laboratory mimics natural evolution and must be based on similar concepts (selectionism and neutralism [58], recognised to have shaped present organisms). Even though there are many successful examples of directed-evolution [2] laboratory enzyme evolution remains highly constrained [59]. Epistasis (i.e. the effects of mutations' interactions on protein functions) can restrict the number of mutational paths leading to fitter protein variants [60] and often resulting in 'rugged' fitness landscapes, where mutations are mutually interdependent and dependent on their context [55]. Some functionally silent or neutral mutations (i.e. permissive mutations including stabilizing mutations - that are not selected) may be necessary to 
allow the subsequent fixation of highly adaptive mutations that would otherwise have either neutral or deleterious effects [61]. Such permissive mutations introduce another dimension of historical contingency to the evolution of new functions.

In this context exploration of (i) multiple starting points (generated by neutral drift [62]) and (ii) multiple trajectories in directed enzyme evolution should avoid evolutionary dead-ends. Indeed if $>10$ millions of variants can be screened in droplets, there is no need to severely bottleneck evolution by choosing only one 'winner' in each round of directed-evolution. Instead of picking 'the best' clone in each round (as most directed evolution approaches do now), a larger variety of clones could be selected (Figure 3) based on more tolerant sorting criteria. Tolerant selections will come up with near neutral mutations [63] that may constitute entry points to the next round of variants generating a greater diversity of mutants. Now more starting points for alternative trajectories exist, possibly overcoming the limits of the evolutionary trajectory constrained to a single path. It remains to be seen whether - instead of a single evolutionary trajectory - several trajectories will then emerge (Figure 3), resulting in better coverage and exploration of sequence space.

(iii) Evolution based on multiple traits. It is now well established that enzymes are capable of performing chemically distinct reactions within the same active site (catalytic promiscuity) [64, 65]. The use of two (or more) fluorescent substrates in droplet compartments (with different emission wavelengths) would enable selection based on several activities at the same time. Now the experimenter can make a considered choice between generalists or specialist enzymes. Given the speculation that generalists are more evolvable (or more central to evolutionary trajectories) imposing such a criterion may change the course and outcome of an evolution campaign. Alternatively, highly specific enzymes could be selected based on the largest possible difference between two readouts to deliberately exclude side activities [66].

(iv) Biocatalyst discovery. Enzyme discovery feeds the pipeline of enzyme engineering by identifying novel starting points for directed evolution. 
Functional metagenomics is a powerful way to identify novel enzymes without relying on existing homologs [67]. However, heterologous expression and the random fragmentation of genomic DNA (that compromises the position of regulatory elements and enzyme-encoding genes) make expression low and hits very rare (estimated as less than 1 in 10,000 variants) [68]. Overcoming the odds with highly sensitive high throughput microdroplets should make this format suitable for screening of metagenomic libraries of unprecedented size [31].

(v) More types of assays needed. The diversity of tasks that can be fulfilled by droplet-based experiments has expanded during the past few years. However most assays require fluorescent products in directed-evolution experiments. Development of new detection systems will be key to target more activities. Adaptation of other optical detection modes will be useful: absorbance measurements can already be carried out in larger droplets $((\varnothing \sim 50 \mu \mathrm{m})$ [69, 70], but will be difficult with path lengths at the $\mu \mathrm{m}$ range (corresponding to the droplet diameter) challenging the Beer-Lambert law. Fluorescence anisotropy [71], Small Angle X-ray Scattering (SAXS) [72], SERS [73], capillary electrophoresis [74] and mass spectrometry [75, 76] are examples of biophysical technics successfully miniaturised in microfluidic droplets. They provide potential additional readouts and enlarge the circle of reactions that can be miniaturised in droplets. Involvement of physicists, chemists and biologists will be required to develop droplet microfluidics further and establish it as a household tool for enzyme engineering.

\section{ACKNOWLEDGMENTS}

Our research was funded by the Biological and Biotechnological Research

Council (BBSRC) and the Engineering and Physical Sciences Research Council (EPSRC). FH is an ERC Starting Investigator, PYC and AZ were 
supported by the EU Marie-Curie training network PhosChemRec. AZ received further support from the BBSRC and the Cambridge European Trust. 


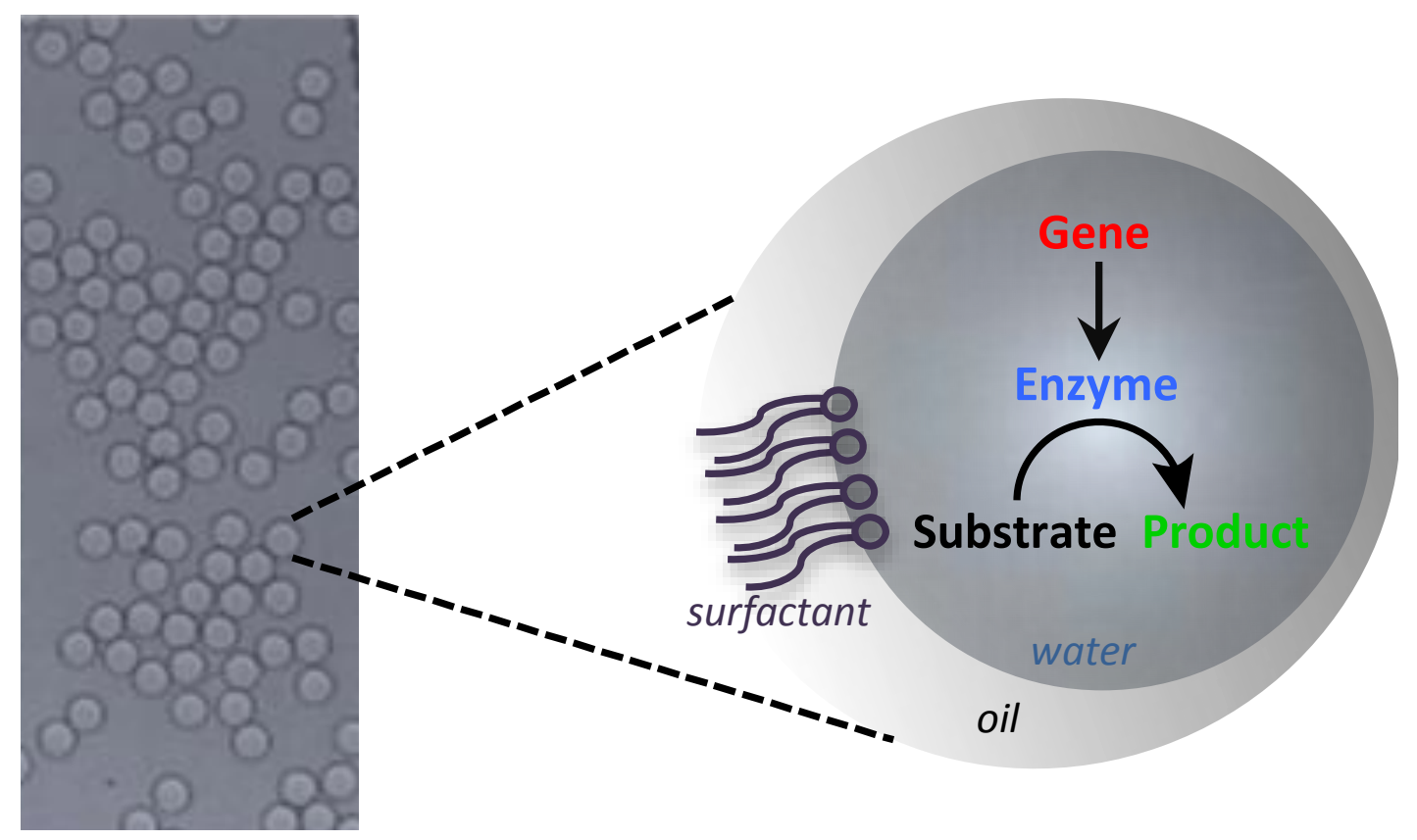

Figure 1. A biomimetic compartment maintaining the linkage of genotype and phenotype. An enzyme encoded by a gene is expressed (see Fig. 2 for the expression formats) and turnover of substrate to product is measured. As the compartment links genotype and phenotype (gene and reaction product, respectively), 'hits' are readily identified by quantification of product, can be selected and decoded after DNA recovery. 
Table 1 Polydisperse and monodisperse compartments used for protein engineering.

\begin{tabular}{|c|c|c|c|c|c|c|}
\hline & \multicolumn{3}{|c|}{ Polydisperse } & \multicolumn{3}{|c|}{ Monodisperse } \\
\hline Species & $\begin{array}{l}\text { Bulk emulsion } \\
\text { droplets }\end{array}$ & $\begin{array}{c}\text { Bulk double emulsion } \\
\text { droplets }\end{array}$ & Liposomes & $\begin{array}{c}\text { Water-in-oil } \\
\text { emulsion droplets }\end{array}$ & $\begin{array}{l}\text { Double emulsion } \\
\text { droplets }\end{array}$ & $\begin{array}{c}\text { Agarose-alginate } \\
\text { gel-shell beads }\end{array}$ \\
\hline $\begin{array}{c}\text { Schematic } \\
\text { representation }\end{array}$ & & & & & & \\
\hline Formation & $\begin{array}{l}\text { Stirring bar [5, 77]; } \\
\text { Vortex [47, 78]; } \\
\text { extruder [12]; } \\
\text { homogenizer [6, 79]; } \\
\text { filter [7] }\end{array}$ & $\begin{array}{c}\text { Vortex [78]; extruder } \\
\text { [12]; homogenizer } \\
\text { [79]; filter [7] }\end{array}$ & $\begin{array}{c}\text { Stirring bar, mixer, } \\
\text { extruder, sonicator } \\
\text { [49]; } \\
\text { Vortex [51] }\end{array}$ & $\begin{array}{l}\text { Microfluidic chip } \\
\text { [80]; jetting [20, } \\
\text { 81], } \\
\text { on-demand [69-71] }\end{array}$ & $\begin{array}{l}\text { Microfluidic chip } \\
\quad[25,26]\end{array}$ & $\begin{array}{c}\text { Microfluidic chip } \\
\text { [27] }\end{array}$ \\
\hline $\begin{array}{c}\text { Droplet } \\
\text { Diameter }(\mu \mathbf{m})\end{array}$ & $\sim 1-20 \mu \mathrm{m}$ & $\sim 1-20 \mu \mathrm{m}$ & $\sim 1-6 \mu \mathrm{m}$ & $\sim 4-200 \mu \mathrm{m}$ & $\sim 20-130 \mu \mathrm{m}^{a}$ & $\sim 18 \mu \mathrm{m}$ \\
\hline $\begin{array}{l}\text { Droplet } \\
\text { Volume }\end{array}$ & $\sim 4-520 \mathrm{fL}$ & $\sim 4-520 \mathrm{fL}$ & $\sim 0.5-110 \mathrm{fL}$ & $\sim 0.03-520 \mathrm{pL}$ & $\sim 1-1150 \mathrm{pL}$ & $\sim 3 \mathrm{pL}$ \\
\hline $\begin{array}{c}\text { Number of } \\
\text { compartments }^{b}\end{array}$ & $10^{11}-10^{7}$ & $10^{11}-10^{7}$ & $10^{11}-10^{8}$ & $10^{9}-10^{6}$ & $10^{7}-10^{4}$ & $10^{7}$ \\
\hline $\begin{array}{l}\text { Time required for } \\
\text { typical experiment }\end{array}$ & $\sim 10 \mathrm{~min}$ & $\sim 10 \mathrm{~min}$ & $\sim 1 \mathrm{~h}$ & $\begin{array}{l}\sim 10 \mathrm{~h} \text { for } 10^{8} \\
\text { compartments }\end{array}$ & $\begin{array}{l}\sim 20 \mathrm{~h} \text { for } 10^{8} \\
\text { compartments }\end{array}$ & $\begin{array}{l}\sim 20 \mathrm{~h} \text { for } 10^{8} \\
\text { compartments }\end{array}$ \\
\hline Directed evolution & [8-10] & [12-14] & [82] & {$[4,30]$} & - & [27] \\
\hline
\end{tabular}

\footnotetext{
a. Diameter of the inner aqueous droplets
}

${ }^{b}$ Emulsion/oil or bead/water mixture in a $1 \mathrm{~mL}$ test tube. 


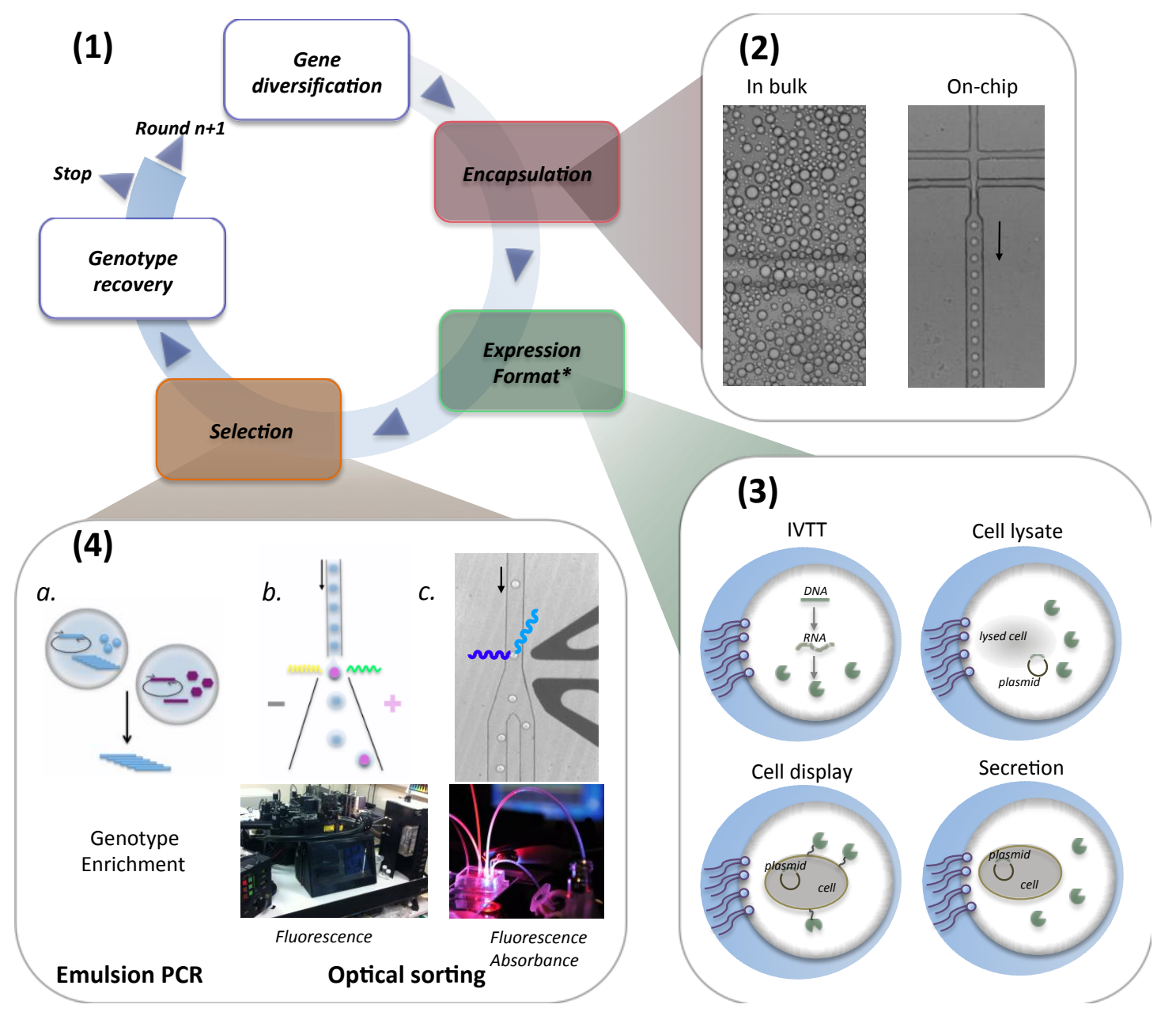

Figure 2: Experimental alternatives for directed-evolution cycles using compartmentalised formats.

(1) Directed-evolution experiments typically start from a diversified parent (made e.g. by error-prone PCR, DNA shuffling or other methods [83]) and the library based on this parent is subsequently screened. (2) Emulsions can be produced in bulk (with high variation in sizes) or "on-chip" using microfluidic devices for highly monodisperse droplets. (3) Emulsions are suitable for a variety of expression systems: in vitro transcription translation (IVTT); miniaturised cell lysate; cell surface display; secretion. (4) Amongst the assay readouts that have been successfully employed for droplet-based selections are (a) self-modification of the coding DNA and, as in (b) and (c), screening for optical properties of the reaction product. (b) Commercial flow cytometers can sort double emulsions based on fluorescence. (c) Sorting in custom-made chips reduces the capital expenditure (but requires specialised skills to operate). In the future sorting chips based on other optical detection techniques (such as absorbance or anisotropy measurements) will become 
available, enlarging the arsenal of possible assays (and thus the number of enzymes that are amenable to directed evolution in this format). 
(1)

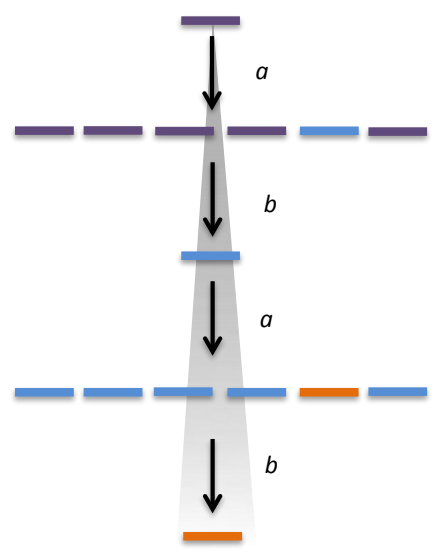

(i)

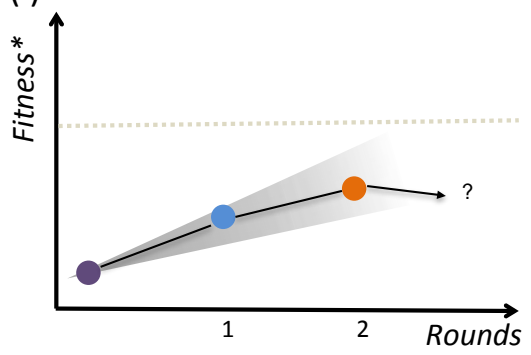

(2)

Round 1

Round 2

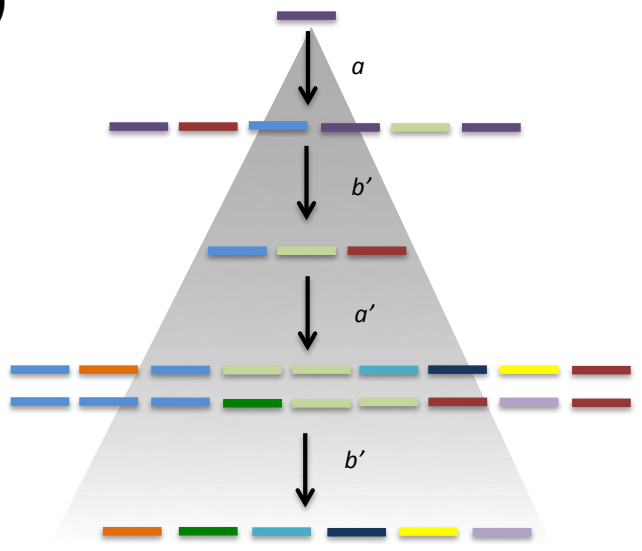

(ii)

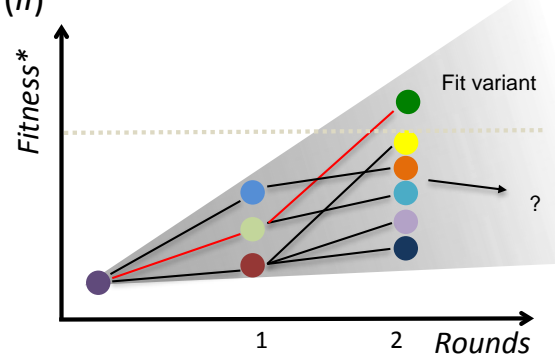

Figure 3: Will ultrahigh-throughput screening enable emergence of multiple evolutionary trajectories?

(1) In the majority of published examples only the one most improved variant is carried into the next round of evolution (for reasons of work economy), diversified and the resulting library screened again. This bottleneck leads to narrow genetic diversity in subsequent rounds. (2) The highly parallelised nature of a droplet-based ultrahigh throughput experiment makes it possible to carry out more permissive selections, with little additional work compared to processing a single selected mutant: instead of just one, many variants can be selected ( $\left.b^{\prime}\right)$, diversified ( $\left.a^{\prime}\right)$ and screened in subsequent rounds. Now much larger, but more diverse libraries need to be screened .The lower hit rate (as result of the more permissive initial selection) and the desire to cover that larger diversity require the use of ultrahigh throughput of droplet-like compartments $\left(\sim 10^{7}\right.$ variants) to identify improved clones.

The lower panel compares two hypothetical scenarios as a result of the experimental protocols (1) or (2): (I) screening throughput and choice of one (or few) mutant(s) in each round limits exploration of sequence space to one evolutionary trajectory at a time; (ii) several evolutionary trajectories are 
explored, resulting in better coverage of sequence space. A specific trajectory that 'takes off' only in later rounds is shown. Under stringent selections this trajectory would be cut short in round 1 (as the mutant did not stand out and others would be chosen in its stead), while this lineage persists under a more permissive selection regime. Such a scenario is relevant when the sequence context changes the contribution of individual residues (epistasis [60]) that could be brought about by near-neutral drifts [84, 85].

*Fitness may be any combination of the following properties that are assayed in each round of directed evolution: activity, specificity, thermostability, solvent stability. 


\section{References}

[1] Bornscheuer, U.T., Huisman, G.W., Kazlauskas, R.J., Lutz, S., Moore, J.C., and Robins, K. (2012). Engineering the third wave of biocatalysis. Nature 485, 185-194.

[2] Turner, N.J. (2009). Directed evolution drives the next generation of biocatalysts. Nat Chem Biol 5, 567-573.

[3] Leemhuis, H., Stein, V., Griffiths, A.D., and Hollfelder, F. (2005). New genotype-phenotype linkages for directed evolution of functional proteins. Curr Opin Struct Biol 15, 472-478.

[4••] Agresti, J.J., Antipov, E., Abate, A.R., Ahn, K., Rowat, A.C., Baret, J.C., Marquez, M., Klibanov, A.M., Griffiths, A.D., and Weitz, D.A. (2010). Ultrahigh-throughput screening in drop-based microfluidics for directed evolution. Proceedings of the National Academy of Sciences of the United States of America 107, 4004-4009.

This paper describes the first directed evolution experiment carried out onchip in monodisperse emulsion droplets by integrating several unit operation in one device.

[5] Tawfik, D.S., and Griffiths, A.D. (1998). Man-made cell-like compartments for molecular evolution. Nature Biotechnology 16, 652-656.

[6] Houlihan, G., Gatti-Lafranconi, P., Kaltenbach, M., Lowe, D., and Hollfelder, F. (2014). An experimental framework for improved selection of binding proteins using SNAP display. J Immunol Methods 405, 47-56.

[7] Devenish, S.R.A. and Hollfelder, F. in preparation.

[8] Ghadessy, F.J., Ong, J.L., and Holliger, P. (2001). Directed evolution of polymerase function by compartmentalized self-replication. Proc. Natl. Acad. Sci. U.S.A. 98, 4552-4557.

[9] Loakes, D., Gallego, J., Pinheiro, V.B., Kool, E.T., and Holliger, P. (2009). Evolving a polymerase for hydrophobic base analogues. J Am Chem Soc 131, 14827-14837.

[10••] Ellefson, J.W., Meyer, A.J., Hughes, R.A., Cannon, J.R., Brodbelt, J.S., and Ellington, A.D. (2014). Directed evolution of genetic parts and circuits by compartmentalized partnered replication. Nature Biotechnology 32, 97-101.

Holliger's compartmentalized self-replication [8] is conceptually extended by linking a circuit for the evolution of another molecule to compartmentalized PCR amplification. In the future regulatory parts for synthetic biology (e.g. transcription factors, repressors or riboswitches) may be evolved in this way, if their function can be coupled to a DNA polymerase production readout.

[11] Bernath, K., Hai, M., Mastrobattista, E., Griffiths, A.D., Magdassi, S., and Tawfik, D.S. (2004). In vitro compartmentalization by double emulsions: sorting and gene enrichment by fluorescence activated cell sorting. Anal Biochem 325, 151-157.

[12] Mastrobattista, E., Taly, V., Chanudet, E., Treacy, P., Kelly, B.T., and Griffiths, A.D. (2005). High-throughput screening of enzyme libraries: in vitro evolution of a beta-galactosidase by fluorescence-activated sorting of double emulsions. Chem Biol 12, 1291-1300.

[13] Aharoni, A., Amitai, G., Bernath, K., Magdassi, S., and Tawfik, D.S. (2005). High-throughput screening of enzyme libraries: thiolactonases evolved by fluorescence-activated sorting of single cells in emulsion compartments. Chem Biol 12, 1281-1289. 
[14] Gupta, R.D., Goldsmith, M., Ashani, Y., Simo, Y., Mullokandov, G., Bar, H., Ben-David, M., Leader, H., Margalit, R., Silman, I., et al. (2011). Directed evolution of hydrolases for prevention of G-type nerve agent intoxication. Nat Chem Biol 7, 120-125.

[15] Kintses, B., van Vliet, L.D., Devenish, S.R., and Hollfelder, F. (2010). Microfluidic droplets: new integrated workflows for biological experiments. Curr. Opin. Chem. Biol. 14, 548-555.

[16] McDonald, J.C., Duffy, D.C., Anderson, J.R., Chiu, D.T., Wu, H., Schueller, O.J.A., and Whitesides, G.M. (2000). Fabrication of microfluidic systems in poly(dimethylsiloxane). Electrophoresis, 27-40.

[17] Mazutis, L., Gilbert, J., Ung, W.L., Weitz, D.A., Griffiths, A.D., and Heyman, J.A. (2013). Single-cell analysis and sorting using droplet-based microfluidics. Nat Protoc 8, 870-891.

[18] Huebner, A., Sharma, S., Srisa-Art, M., Hollfelder, F., Edel, J.B., and Demello, A.J. (2008). Microdroplets: a sea of applications? Lab on a chip 8, 1244-1254.

[19] Theberge, A.B., Courtois, F., Schaerli, Y., Fischlechner, M., Abell, C., Hollfelder, F., and Huck, W.T. (2010). Microdroplets in microfluidics: an evolving platform for discoveries in chemistry and biology. Angew Chem Int Ed Engl 49, 5846-5868.

[20] Shim, J., Ranasinghe, R.T., Smith, C.A., Ibrahim, S.M., Hollfelder, F., Huck, W.T., Klenerman, D., and Abell, C. (2013). Utrarapid generation of femtoliter microfluidic droplets for single-molecule-counting immunoassays. ACS Nano 7, 5955-5964.

[21] Baret, J.C., Miller, O.J., Taly, V., Ryckelynck, M., El-Harrak, A., Frenz, L., Rick, C., Samuels, M.L., Hutchison, J.B., Agresti, J.J., et al. (2009). Fluorescence-activated droplet sorting (FADS): efficient microfluidic cell sorting based on enzymatic activity. Lab on a chip 9, 1850-1858.

[22] Schmid, L., Weitz, D.A., and Franke, T. (2014). Sorting drops and cells with acoustics: acoustic microfluidic fluorescence-activated cell sorter. Lab on a chip 14, 3710-3718.

[23] Sciambi, A., and Abate, A.R. (2015). Accurate microfluidic sorting of droplets at $30 \mathrm{kHz}$. Lab on a chip 15, 47-51.

[24] Adams, L.L.A., Kodger, T.E., Kim, S.-H., Shum, H.C., Franke, T., and Weitz, D.A. (2012). Single step emulsification for the generation of multicomponent double emulsions. Soft Matter 8, 10719.

[25] Bauer, W.A., Fischlechner, M., Abell, C., and Huck, W.T. (2010). Hydrophilic PDMS microchannels for high-throughput formation of oil-in-water microdroplets and water-in-oil-in-water double emulsions. Lab on a chip 10, 1814-1819.

[26] Zinchenko, A., Devenish, S.R., Kintses, B., Colin, P.Y., Fischlechner, M., and Hollfelder, F. (2014). One in a million: flow cytometric sorting of single cell-lysate assays in monodisperse picolitre double emulsion droplets for directed evolution. Anal. Chem. 86, 2526-2533.

[27•] Fischlechner, M., Schaerli, Y., Mohamed, M.F., Patil, S., Abell, C., and Hollfelder, F. (2014). Evolution of enzyme catalysts caged in biomimetic gelshed beads. Nature Chem. 6, 791-796.

[28•] Wang, B.L., Ghaderi, A., Zhou, H., Agresti, J., Weitz, D.A., Fink, G.R., and poulos, G. (2014). Microfluidic high-throughput culturing of single cells for selection based on extracellular metabolite production or consumption. Nat. Biotech. 32, 473-478. 
Xylose-overconsuming Saccharomyces cerevisiae and L-lactateproducing Escherichia coli clones compartmentalised in droplets are enriched $10^{3}-10^{4}$-fold as examples of screening for extracellular metabolite levels. Here two steps, cell culture and activity assay, were integrated in one device.

[29] Sjostrom, S.L., Bai, Y., Huang, M., Liu, Z., Nielsen, J., Joensson, H.N., and Andersson Svahn, H. (2014). High-throughput screening for industrial enzyme production hosts by droplet microfluidics. Lab on a chip 14, 806-813. [30•] Kintses, B., Hein, C., Mohamed, M.F., Fischlechner, M., Courtois, F., Laine, C., and Hollfelder, F. (2012). Picoliter cell lysate assays in microfluidic droplet compartments for directed enzyme evolution. Chem Biol 19, 10011009.

The most widespread directed evolution format, cell lysate assays, has been miniaturised to the droplet format and the utility of this system is shown by successful directed evolution experiments for both higher activity and protein expression.

[31] Colin, P.Y., Kintses, B., Gielen, F., Miton, C., Mohamed, M., Fischer, G., Morgavi, D.P., Janssen, D.B., Hyvonen, M. and Hollfelder, F. (2015). unpublished results.

[32] Abate, A.R., Hung, T., Mary, P., Agresti, J.J., and Weitz, D.A. (2010). High-throughput injection with microfluidics using picoinjectors. Proc Natl Acad Sci U S A 107, 19163-19166.

[33] Beneyton, T., Coldren, F., Baret, J.C., Griffiths, A.D., and Taly, V. (2014). CotA laccase: high-throughput manipulation and analysis of recombinant enzyme libraries expressed in E. coli using droplet-based microfluidics. Analyst. 139, 3314-3323.

[34] Shimizu, Y., Inoue, A., Tomari, Y., Suzuki, T., Yokogawa, T., Nishikawa, K., and Ueda, T. (2001). Cell-free translation reconstituted with purified components. Nat. Biotech. 19, 751-755.

[35] Cohen, H.M., Tawfik, D.S., and Griffiths, A.D. (2004). Altering the sequence specificity of Haelll methyltransferase by directed evolution using in vitro compartmentalization. Protein Eng Des Sel 17, 3-11.

[36] Courtois, F., Olguin, L.F., Whyte, G., Bratton, D., Huck, W.T., Abell, C., and Hollfelder, F. (2008). An integrated device for monitoring time-dependent in vitro expression from single genes in picolitre droplets. ChemBioChem 9 , 439-446.

[37] Fallah-Araghi, A., Baret, J.-C., Ryckelynck, M., and Griffiths, A.D. (2012). A completely in vitro ultrahigh-throughput droplet-based microfluidic screening system for protein engineering and directed evolution. Lab on a chip, 12(5):882-91.

[38] Mazutis, L., Araghi, A.F., Miller, O.J., Baret, J.C., Frenz, L., Janoshazi, A., Taly, V., Miller, B.J., Hutchison, J.B., Link, D., et al. (2009). Droplet-based microfluidic systems for high-throughput single DNA molecule isothermal amplification and analysis. Anal Chem 81, 4813-4821.

[39] Struder, A., Hadida, S., Ferritto, R., Kim, S.-Y., Jeger, P., Wipf, P., and Curran, D.P. (1997). Fluorous synthesis: A fluorous-Phase strategy for improving separation efficiency in organic synthesis. Science 275, 823-826.

[40] Clausell-Tormos, J., Lieber, D., Baret, J.C., El-Harrak, A., Miller, O.J., Frenz, L., Blouwolff, J., Humphry, K.J., Koster, S., Duan, H., et al. (2008). Droplet-based microfluidic platforms for the encapsulation and screening of Mammalian cells and multicellular organisms. Chem Biol 15, 427-437. 
[41] Holtze, C., Rowat, A.C., Agresti, J.J., Hutchison, J.B., Angile, F.E., Schmitz, C.H., Koster, S., Duan, H., Humphry, K.J., Scanga, R.A., et al. (2008). Biocompatible surfactants for water-in-fluorocarbon emulsions. Lab on a chip 8, 1632-1639.

[42] Skhiri, Y., Gruner, P., Semin, B., Brosseau, Q., Pekin, D., Mazutis, L., Goust, V., Kleinschmidt, F., El Harrak, A., Hutchison, J.B., et al. (2012). Dynamics of molecular transport by surfactants in emulsions. Soft Matter 8 , 10618.

[43] Courtois, F., Olguin, L.F., Whyte, G., Theberge, A.B., Huck, W.T., Hollfelder, F., and Abell, C. (2009). Controlling the retention of small molecules in emulsion microdroplets for use in cell-based assays. Anal Chem 81, 3008-3016.

[44] Najah, M., Mayot, E., Mahendra-Wijaya, I.P., Griffiths, A.D., Ladame, S., and Drevelle, A. (2013). New glycosidase substrates for droplet-based microfluidic screening. Anal Chem 85, 9807-9814.

[45] Woronoff, G., El Harrak, A., Mayot, E., Schicke, O., Miller, O.J., Soumillion, P., Griffiths, A.D., and Ryckelynck, M. (2011). New generation of amino coumarin methyl sulfonate-based fluorogenic substrates for amidase assays in droplet-based microfluidic applications. Anal. Chem. 83, 2852-2857. [46] Zinchenko, A., Devenish, S.R., and Hollfelder, F. (2015). Rapid quantitative assessment of leakage of assay components from microdroplet to test the suitability of oil/surfactant combinations. Submitted.

[47] Kaltenbach, M., Devenish, S.R., and Hollfelder, F. (2012). A simple method to evaluate the biochemical compatibility of oil/surfactant mixtures for experiments in microdroplets. Lab on a chip 12, 4185-4192.

[48] Blain, J.C., and Szostak, J.W. (2014). Progress toward synthetic cells. Annu Rev Biochem 83, 615-640.

[49] Pautot, S., Frisken, B.J., and Weitz, D.A. (2003). Production of unilamellar vesicles using an inverted emulsion. Langmuir 19, 2870-2879.

[50] Fujii, S., Matsuura, T., Sunami, T., Kuzata, Y., and Yomo, T. (2013). In vitro evolution of a-hemolysin using a liposome display. Proc. Natl. Acad. Sci. U S A 110, 16796-16801.

[51••] Fujii, S., Matsuura, T., Sunami, T., Nishikawa, T., Kazuta, Y., and Yomo, T. (2014). Liposome display for in vitro selection and evolution of membrane proteins. Nat. Protoc. 9, 1578-1591.

Membrane proteins are hard to work with and have rarely been subjected to directed evolution. This method makes such proteins amenable to highthroughput screening, demonstrated by selection for pore-forming activity of a-hemolysin.

[52] Ichihashi, N., Usui, K., Kazuta, Y., Sunami, T., Matsuura, T., and Yomo, T. (2013). Darwinian evolution in a translation-coupled RNA replication system within a cell-like compartment. Nat Commun 4, 2494.

[53] Araya, C.L., and Fowler, D.M. (2011). Deep mutational scanning: assessing protein function on a massive scale. Trends Biotechnol 29, 435-442. [54] Tokuriki, N., and Tawfik, D.S. (2009). Chaperonin overexpression promotes genetic variation and enzyme evolution. Nature 459, 668-673.

[55] Romero, P.A., and Arnold, F.H. (2009). Exploring protein fitness landscapes by directed evolution. Nat Rev Mol Cell Biol 10, 866-876.

[56] Fowler, D.M., and Fields, S. (2014). Deep mutational scanning: a new style of protein science. Nat Methods 11, 801-807. 
[57] Fowler, D.M., Stephany, J.J., and Fields, S. (2014). Measuring the activity of protein variants on a large scale using deep mutational scanning. Nat Protoc 9, 2267-2284.

[58] Wagner, A. (2008). Neutralism and selectionism: a network-based reconciliation. Nat. Rev. Genet. 9, 965-974.

[59] Kaltenbach, M., and Tokuriki, N. (2014). Dynamics and constraints of enzyme evolution. Journal of Experimental Zoology. Part B, Mol. Dev. Evol. 322, 468-487.

[60] Weinreich, D.M., Delaney, N.F., Depristo, M.A., and Hartl, D.L. (2006). Darwinian evolution can follow only very few mutational paths to fitter proteins. Science 312, 111-114.

[61] Harms, M.J., and Thornton, J.W. (2014). Historical contingency and its biophysical basis in glucocorticoid receptor evolution. Nature 512, 203-207.

[62] Bershtein, S., Goldin, K., and Tawfik, D.S. (2008). Intense neutral drifts yield robust and evolvable consensus proteins. J Mol Biol 379, 1029-1044.

[63] Akashi, H., Osada, N., and Ohta, T. (2012). Weak selection and protein evolution. Genetics 192, 15-31.

[64] Babtie, A.C., Tokuriki, N., and Hollfelder, F. (2010). What makes an enzyme promiscuous? Curr. Opin. Chem. Biol. 14, 200-207.

[65] O'Brien, P.J., and Herschlag, D. (1999). Catalytic promiscuity and the evolution of new enzymatic activities. Chem. Biol. 6, 91-105.

[66] Collins, C.H., Leadbetter, J.R., and Arnold, F.H. (2006). Dual selection enhances the signaling specificity of a variant of the quorum-sensing transcriptional activator LuxR. Nature Biotechnol 24, 708-712.

[67] Handelsman, J. (2004). Metagenomics: Application of genomics to uncultured microorganisms. Microbiol. Mol. Biol. Rev. 68, 669-685.

[68] Gabor, E.M., Alkema, W.B., and Janssen, D.B. (2004). Quantifying the accessibility of the metagenome by random expression cloning techniques. Environ. Microbiol. 6, 879-886.

[69] Gielen, F., Buryska, T., Vliet, L.V., Butz, M., Damborsky, J., Prokop, Z., and Hollfelder, F. (2015). Interfacing microwells with nanoliter compartments: a sampler generating high-resolution concentration gradients for quantitative biochemical analyses in droplets. Anal Chem 87, 624-632.

[70•] Gielen, F., van Vliet, L., Koprowski, B.T., Devenish, S.R., Fischlechner, M., Edel, J.B., Niu, X., deMello, A.J., and Hollfelder, F. (2013). A fully unsupervised compartment-on-demand platform for precise nanoliter assays of time-dependent steady-state enzyme kinetics and inhibition. Anal. Chem. 85, 4761-4769.

The quantitative characterisation of selected enzymes is the necessary follow-up of any directed evolution campaign. Here (and in [69] kinetic assays with varying reagent concentrations are miniaturised into droplets and carried out in semi-automated fashion - to give data of excellent quality. The Implementation of absorbance assays shows that this detection mode can also be used in droplets, paving the way for absorbance-based selections in the future.

[71] Cheow, L.F., Viswanathan, R., Chin, C.S., Jennifer, N., Jones, R.C., Guccione, E., Quake, S.R., and Burkholder, W.F. (2014). Multiplexed analysis of protein-ligand interactions by fluorescence anisotropy in a microfluidic platform. Anal Chem 86, 9901-9908. 
[72] Stehle, R., Goerigk, G., Wallacher, D., Ballauff, M., and Seiffert, S. (2013). Small-angle X-ray scattering in droplet-based microfluidics. Lab on a chip 13, 1529-1537.

[73] Hidi, I.J., Jahn, M., Weber, K., Cialla-May, D., and Popp, J. (2015).

Droplet based microfluidics: spectroscopic characterization of levofloxacin and its SERS detection. Phys. Chem. Chem. Phys. DOI: 10.1039/c4cp04970e

[74] Niu, X., Pereira, F., Edel, J.B., and de Mello, A.J. (2013). Dropletinterfaced microchip and capillary electrophoretic separations. Anal Chem 85, 8654-8660.

[75] Smith, C.A., Li, X., Mize, T.H., Sharpe, T.D., Graziani, E.I., Abell, C., and Huck, W.T. (2013). Sensitive, high throughput detection of proteins in individual, surfactant-stabilized picoliter droplets using nanoelectrospray ionization mass spectrometry. Anal Chem 85, 3812-3816.

[76] Sun, S., and Kennedy, R.T. (2014). Droplet electrospray ionization mass spectrometry for high throughput screening for enzyme inhibitors. Anal Chem 86, 9309-9314.

[77] Griffiths, A.D., and Tawfik, D.S. (2003). Directed evolution of an extremely fast phosphotriesterase by in vitro compartmentalization. EMBO J. 22, 24-35.

[78] Lim, S.W., and Abate, A.R. (2013). Ultrahigh-throughput sorting of microfluidic drops with flow cytometry. Lab on a chip 13, 4563-4572.

[79] Prodanovic, R., Ostafe, R., Blanusa, M., and Schwaneberg, U. (2012). Vanadium bromoperoxidase-coupled fluorescent assay for flow cytometry sorting of glucose oxidase gene libraries in double emulsions. Anal Bioanal Chem 404, 1439-1447.

[80] Huebner, A., Olguin, L.F., Bratton, D., Whyte, G., Huck, W.T., de Mello, A.J., Edel, J.B., Abell, C., and Hollfelder, F. (2008). Development of quantitative cell-based enzyme assays in microdroplets. Anal Chem 80, 38903896.

[81] Umbanhowar, P.B., Prasad, V., and Weitz, D.A. (2000). Monodisperse emulsion generation via drop break off in a coflowing stream. Langmuir 16, 347-351.

[82] Fujii, S., Matsusra, T., Sunami, T., Kazuta, Y., and Yomo, T. (2013). In vitro evolution of $\alpha$-hemolysin using a liposome display. Proc. Natl. Acad. Sci. U S A 110, 16796-16801.

[83] Gillam, E.M.J., Copp, J.N., and Ackerley, D.F. (2014). Directed Evolution Library Creation: Methods and Protocols, (Humana Press).

[84] Amitai, G., Gupta, R.D., and Tawfik, D.S. (2007). Latent evolutionary potentials under the neutral mutational drift of an enzyme. HFSP Journal 1 , 67-78.

[85] Bloom, J.D., Romero, P.A., Lu, Z., and Arnold, F.H. (2007). Neutral genetic drift can alter promiscuous protein functions, potentially aiding functional evolution. Biology Direct 2, 17. 